\title{
Opportunities and Differences of Open Government Data Policies in Europe
}

\author{
By Giuseppe Reale
}

The paper presents an analysis of the Open Government paradigm connecting it with the big political and social challenges of the traditional democratic institutions. The recent crisis in the representation of interests regarding in particular trade unions or political parties put in evidence the emerging role of the "CitizenConsumer", thanks to the new possibilities offered by the web 2.0. A similar transformation of citizens behavior needs a revision of the culture of public administration from a closed and self-referential system to an open system able to adapt to the pressing bottom-up requests of transparency, participation and collaboration. The following analysis, focused on the Open Data phenomenon from its birth to the recent developments, tries to put in evidence the differences between some European countries, and the emerging gaps, using the neo-institutionalist approach.

\section{Open Gov and Open Data between web 2.0 and a New Conception of Citizenship}

The recent crisis in the representation of interests, such as trade unions or political parties, gives an unprecedented centrality of citizen empowerment, not only as a voter or as a taxpayer but as an active player (Micheletti et al., 2004) that act in an increasingly fluid society (Bauman, 2002), in the so called "Citizen-Consumer" perspective (Cohen 2001, p.220). The involvement of citizens in public decision-making, especially at the local level, responds to urgent needs such as reprogramming and implementing public policies increasingly specific, overcoming the vicious cycle of welfare dependency. In this sense, promoting proactive logics of citizens participation becomes strategic for the enhancement of existing resources, such as networks and social capital, ensuring the effectiveness and sustainability of social interventions.

Web 2.0 is a key protagonist of this "liquid" citizenship, which led to a technological revolution that strengthen the leadership of the consumer-user and the information capital at its disposal, promoting new forms of exchange and aggregation. Internet, as an interactive and customer driven tool, encourages an exercise of citizenship without spatial limits, according to a "glocal" logic (Beck, 1999). The web is the connective tissue that brings

${ }^{*}$ Ph.D. fellow, University of Catania (Department of Political and Social Sciences), Italy.

https://doi.org/10.30958/ajss.1-3-3

doi=10.30958/ajss.1-3-3 
together the different possible dimensions of this new conception of citizenship (individual and collective, global and local, virtual and real).

A similar transformation of citizens behavior needs a revision of the culture of public administration (PA), without which the transformations described above cannot be fulfilled. This change goes beyond the "atomistic" conception of the public administration, as a closed and self-referential system, towards a new PA an "open system" (Freeman, 1984), in continual interchange with the environment, exploiting the new opportunities of "collective intelligence" (Lévy, 2008, p.154) or "open innovation systems" (Chesbrough, 2003), also in a crowdsourcing logic (Howe, 2006). This means (Arcidiacono and Reale, 2010):

- redefining the boundaries between public and private both in the construction and definition of collective well-being (consider, for example, the concept of Community Welfare);

- internalizing at the same time the principles of corporate social responsibility (CSR) also in $\mathrm{PA}$;

- changing the logic of production according to an open source model based on information sharing and citizen participation, building a system of evaluation and monitoring of their needs and their opinions able to achieve a new model of accountability.

In this sense, the most important example of changing in the relationship between government and citizen-user is then the phenomenon of Open Data (OD), which aims to make accessible the data produced by the government through the release of datasets in open format.

According to Open Knowledge Foundation, Open Data are "freely used, reused and redistributed, with the only limitation - at best - of citation of the author" (opendatamanual.org). The definition cited above, focuses on access to data that must not only be made available online in an intelligible and editable format, but above all they must be released without restrictions that limit the re-use, the integration with other data (linked open data) and also the redistribution for commercial purposes. This model implies a revision of the traditional user licenses as well as the concepts of copyright, patents and Privacy Policy. The Open Data become a crucial point in order to implement the principles of Open Government (OG) and stimulate collaborative models between local institutions and communities with the aims not only to supervise the actions of the PA but also to the development of new services and applications according to the logic of co-production. Open Data can be seen as a necessary step, considering of the rapid spread of institutional Open Data portals since 2009 (eg, the U.S.A. portal data.gov) until today (62 countries participate at the Open Government Partnership). However, it is clear that this is not enough without a strong change on the organizational models of the traditional bureaucratic systems (AIPG, 2011). It means releasing the so-called Public Sector Information (PSI), non-personal and anonymized, that governments produce in the performance of their institutional tasks and which, 
if made available, they are able of increasing transparency and fostering collaborative interaction between citizens and government.

The European Commission's Communication "Open Data, an engine for innovation, growth and transparent governance", part of the European Strategy for Open Data presented in 2011 by Neelie Kroes (European Commissioner for the Digital Agenda) emphasizes how the availability and accessibility of the PSI is a pre-requisite for economic growth in the euro-zone and for the efficiency and effectiveness of PA. However, the real critical points are the claim self-referentiality of the public administration in relation to its internal processes and the unwarranted privacy principle that continues to surround its allocation decisions and its strategic and operational actions. Moreover, it is necessary underlying the importance of investments in broadband, in the computerization and digitization as well as the implementation of more effective policies for reducing digital divide and enhancing computer literacy.

However, the Open Government paradigm have to face the limits of the so-called "digital democracy" or "limitless democracy " (Rodotà, 2004). The fundamental role of the internet and how this changes the Western democracies has often been exaggerated, creating a sort of positive myth of WEB (e.g. considering authors such as Dewey, Lippman, Latour) that, promising to break down every informative taboo, strengthening a new model of direct democracy. It has to be considered how the Web is a chaotic "container" of data which source or level of renovation is not always detectable. A conscious use of the potentiality of the Net cannot be separated by the possession of suitable skills and capabilities, capable of revealing its ambiguities and risks. The Web, in fact, help to feed even the risk of information overload for citizens, that does not eliminate but rather empower the role of 'mediators' in orienting interpretations and actions. The new media technologies, in fact, despite a rhetoric of autonomy and freedom, would make the subject even more controlled and manipulated (Morozov, 2011), also shown by the debate on net neutrality (Marsden, 2009).

\section{Method}

The work presented proposes a comparative analysis of the Open Data reality at European level, on the basis of official data available (OECD 2013; Open Data Barometer, 2013), according to the three key dimensions of the Open Government Data Systems (defined in the Memorandum for the Heads of Executive Departments and Agencies on Transparency and Open Government ${ }^{1}$ issued by the Obama Administration in 2009): transparency, participation and collaboration.

It is a not easy tentative because it is a new issue and an ever-changing phenomenon that is affected by strong regional differences inside countries, very difficult to grasp.

\footnotetext{
${ }^{1}$ http://www.whitehouse.gov/the_press_office/TransparencyandOpenGovernment
} 
In particular OECD survey (2013) on Open Government Data will be useful to compare open data policies and dataset disclosure in order to understand the different kind of national initiatives among the 28 countries analyzed, at central or local level, and the more spread typologies in the group of the OECD countries. We'll also make reference to Eurostat database, that collects data from the different national statistics offices, about the usage of internet for online consultations or voting, in order to point out the performance of the different countries.

Finally, the Open Data Barometer index developed by the Open Data Institute (ODI) and The Web Foundation, combining expert survey and secondary data focusing on national governments, is a really interesting source because it measures the adoption level of open data policies and their emerging effects in 77 countries through a multidimensional analysis (2013) based on three sub-indices:

1) readiness: it evaluates how a nation is able to take advantage of government data disclosure in order to create positive effects at governmental, business and civil society level;

2) implementation: it measures the level of key data-sets, released by governments, useful in supporting: digital economy and innovation, transparency and accountability of public administrations, effectiveness and efficiency of social policies;

3) emerging impacts: it tries to quantify the positive impact of opening data initiatives in political, social and economic fields (eg: the gain in administrative efficiency, the number of new startup or the increased inclusion of marginalized social groups).

Furthermore, each sub-index proposed is composed by three subcomponents scores useful for evidencing the different performances of the considered countries in a comparative analysis perspective.

\section{Finding}

From 2013, 56\% of OECD countries have a national strategy on Open Data, a $42 \%$ have adopted OD policies in only a few areas of the public administration while only $4 \%$ of the OECD countries currently lacks a strategy about Open Data (see figure 1). 
Figure 1. OECD Countries Approach to OGD (2013)

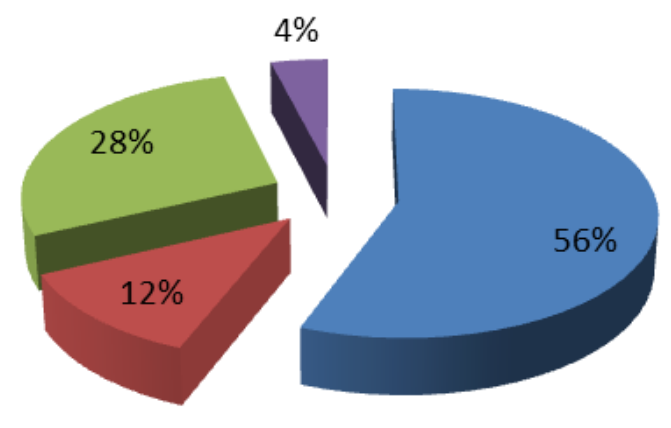

\author{
- National Strategy on OGD \\ - Sectorial OGD Strategies \\ National and Sectorial \\ OGD Strategies \\ no OGD strategy
}

Source: re-elaboration of OECD data (2014)

The United States data.gov is clearly the first example and model of open data portal, created in 2009, after the Obama's Directive on the OG, as a policy for increasing transparency and, at the same time, an initiative to face the crisis by supporting the development of the digital economy. Only a few months later, after the opening of the USA data.gov, the British portal was opened and then also the New Zealand one. This demonstrates how the liberal market economies are the first movers of Open Data initiatives around the world. In fact, only between 2011/2012 the rest of the European countries (both Continental and Mediterranean ones) begin to adopt national Open Data portals.

according the OECD Survey on Open Government Data, that consider the disclosure of datasets with characteristics of greater openness regarding the format used for the release on the web, the advantage the liberal market economies as first movers is also demonstrated by the high rate of dataset disclosure on OD portals: for example in Canada, in 2013, we have more than 188.000 of datasets opened against the only 4.385 of Netherland (see figure 2).

If we look at the Mediterranean countries, this rate is almost lower with 944 open dataset in Spain and only 347 in Italy 
Figure 2. Datasets in National Open Government Data Portal (2013)

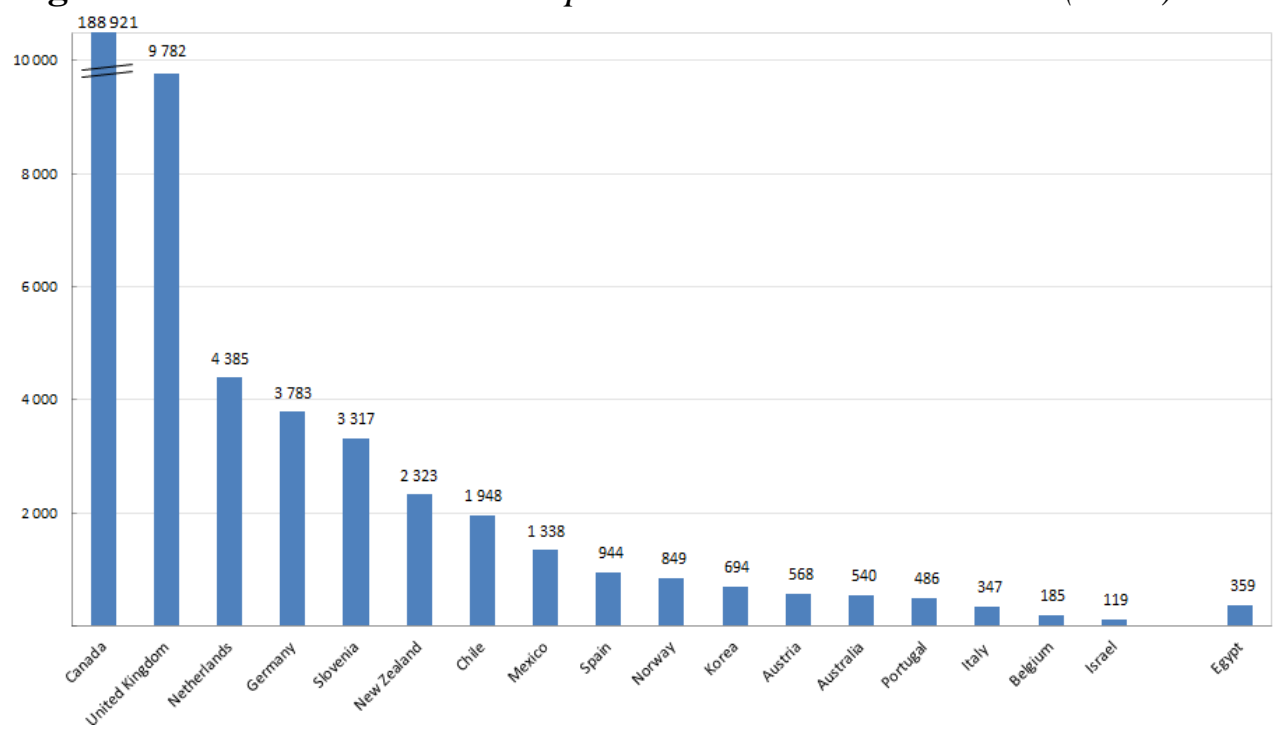

Source: 2013 OECD Survey on Open Government Data

If we look specifically at the European case, thanks to the recent Eurostat data (see figure 3), the use of the web for political participation, for example in online consultation or voting experiences are not developed in the majority of the Continent. On this issue, European countries have lower percentage than the OECD average. In the Mediterranean countries such as Italy, Spain and Greece the percentage of citizens that took part in a on line consultation or online voting is equal to half of what observed in countries like Germany, Norway and Finland: almost 6\%. However, this result seems to put in evidence an European civil society less prepared to OD policies and to a new relationship with a public administration 2.0.

Figure 3. Participation in On-line Consultation or Voting (\% - 2011)

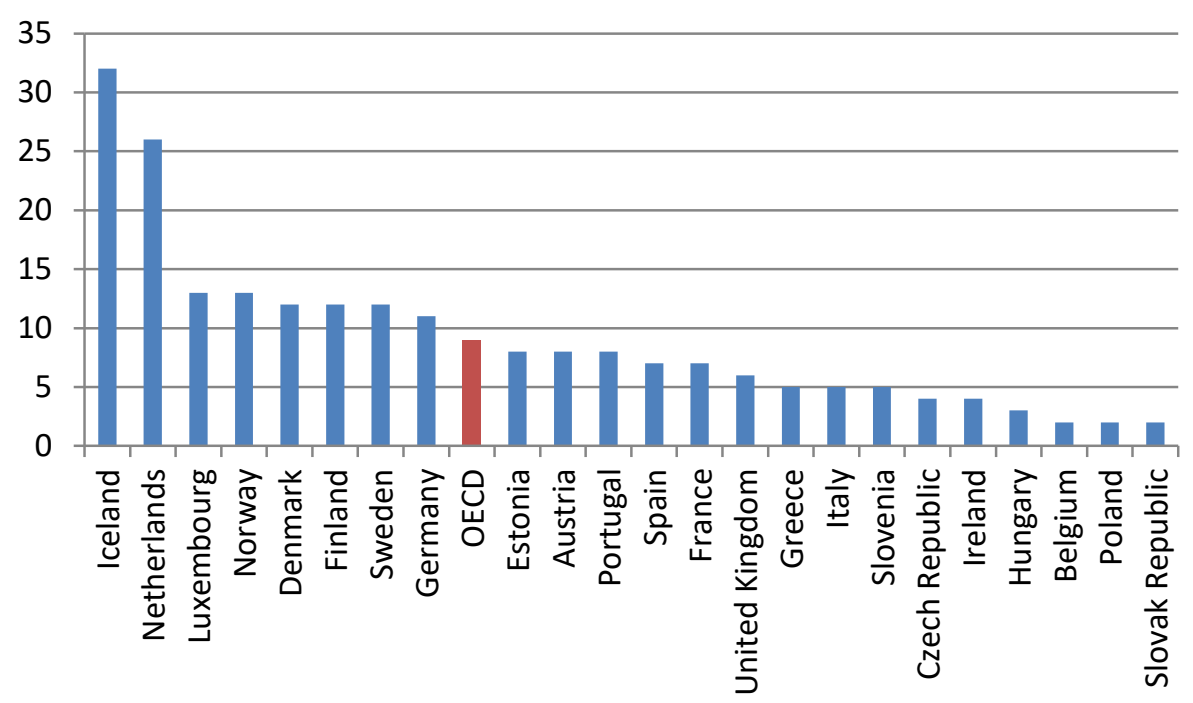

Source: Eurostat (2013) 
Different conclusions, instead, are stressed by the Open Data Barometer Report (2013) that shows how the European Continent is the most effective institutional environment for Open Data policies: Europe has the highest rank not only in the level of development of the right to information but also in the number of OGD initiatives and in governmental support to OD, also at the local level, showing in addition the highest demand for open data initiatives from the civil society. In this ranking (see table 1), Europe has higher performances than Americas, despite in this continent there is the birth country of OD initiatives (USA).

Table 1. Regional Differences from the Open Data Barometer Survey

\begin{tabular}{|c|c|c|c|c|c|}
\hline Regions & $\begin{array}{c}\text { Right to } \\
\text { information } \\
\text { low }\end{array}$ & $\begin{array}{c}\text { OGD } \\
\text { initiative }\end{array}$ & $\begin{array}{c}\text { Demand from } \\
\text { civil society \& } \\
\text { technologists }\end{array}$ & $\begin{array}{c}\text { Government } \\
\text { support for } \\
\text { OGD } \\
\text { innovation }\end{array}$ & $\begin{array}{c}\text { City or } \\
\text { regional } \\
\text { OGD }\end{array}$ \\
\hline Africa & 35.71 & 28.75 & 28.10 & 14.81 & 5.29 \\
\hline Americas & 60.77 & 50.77 & 42.31 & 29.06 & 34.19 \\
\hline $\begin{array}{c}\text { Asia } \\
\text { Pacific }\end{array}$ & 56.92 & 50.00 & 46.15 & 29.06 & 23.93 \\
\hline Europe & 61.36 & 55.45 & 61.82 & 38.89 & 47.47 \\
\hline $\begin{array}{c}\text { Middle } \\
\text { East \& C. } \\
\text { Asia }\end{array}$ & 22.50 & 38.75 & 21.25 & 8.33 & 8.33 \\
\hline TOTAL & $\mathbf{4 9 . 4 8}$ & $\mathbf{4 4 . 6 8}$ & $\mathbf{4 2 . 4 7}$ & $\mathbf{2 5 . 8 3}$ & $\mathbf{2 5 . 6 9}$ \\
\hline
\end{tabular}

Source: Web Foundation, Open Data Barometer (2013)

More interesting results comes from the Open Data Institute with an analysis that tries to measure the adoption level of OD policies through a multidimensional index based on 3 sub-indexes: readiness, implementation and emerging impacts.

In Euro Barometer's ranking UK (see figure 4) is the first country for OGD policies with the highest level of readiness, implementation and impact, overcame only by Sweden, third with a lower level of readiness and implementation but the best impact at the social level. It is not a surprising result for a country with an universalistic welfare regime with an inclusive labor regulation and with a corporatist system.

However, the liberal market economies like UK seems to have an institutional advantage for OGD initiatives thanks to an higher level of computer literacy and an higher level of development of the ICT sector, together with a strong tradition of consumerist movement and high level of consumer protection. 
Figure 4. Comparison of UK and Europe in the Open Data Barometer (2013)

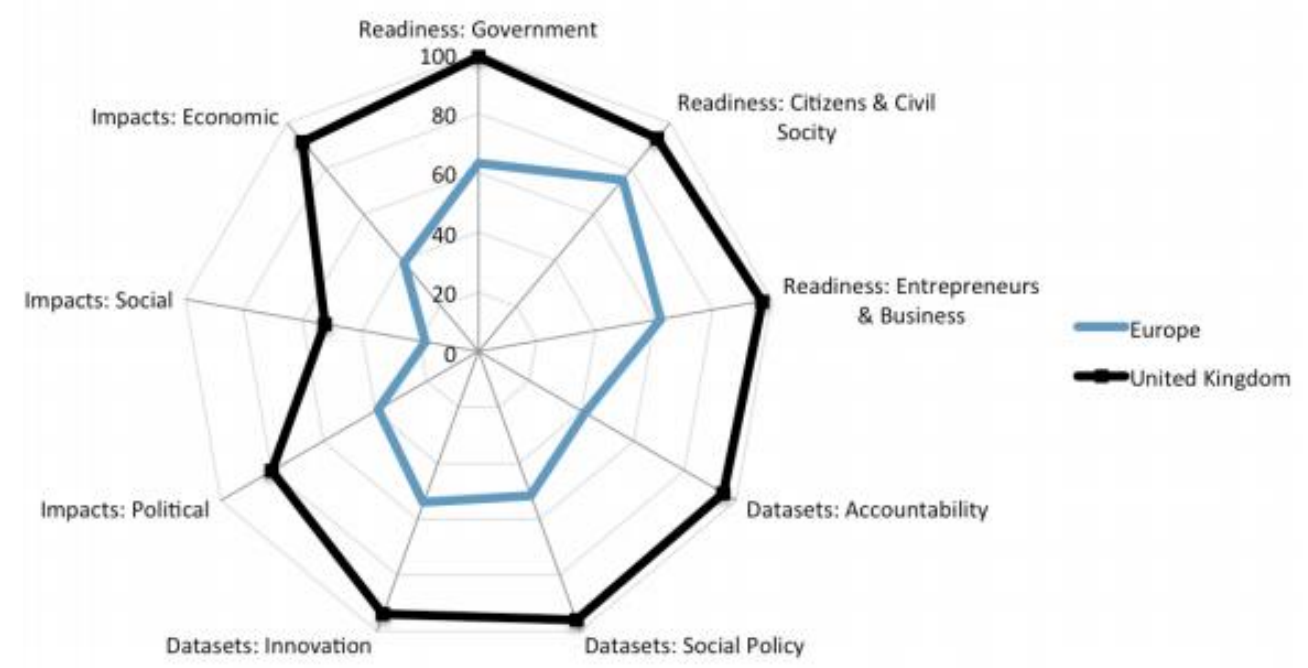

Source: Web Foundation, 2013 Open Data Barometer Global report (p. 27)

If we look at the Mediterranean countries, it is clear a strong gap respect to a liberal country like UK or the Scandinavian countries, like Sweden, Denmark, Finland and Norway. Greece for example is only 37th in the Barometer Index with the lowest rate of readiness above all at the governmental and at the business level, a scarce implementation of OGD policies and an even worst level of impact (see figure 5).

Figure 5. The Greek Case in the Open Data Barometer (2013)

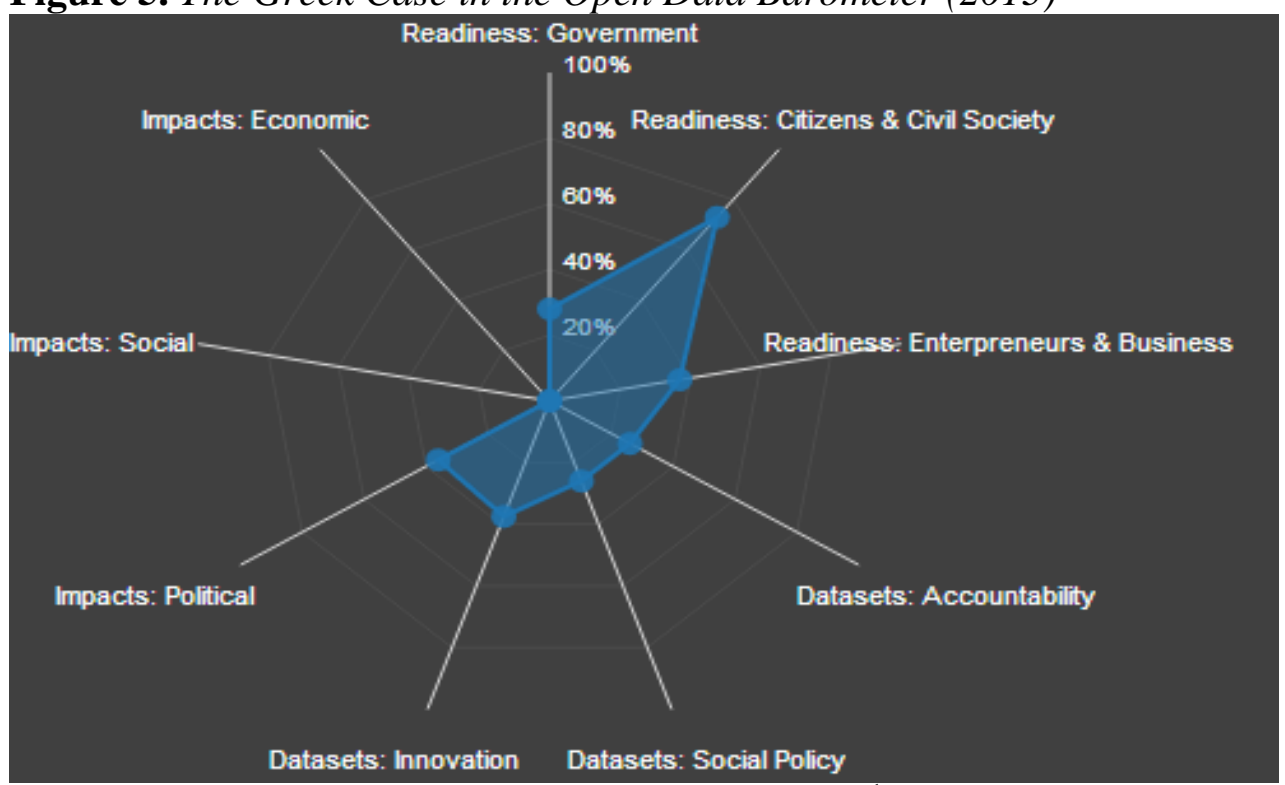

Source: Open Data Institute, 2013 Open Data Barometer Data

${ }^{1}$ Visualization of the Open Data Barometer report data http://theodi.github.io/open-databarometer-viz/ 
The Italian case (see figure 6), despite in a better position in the barometer ranking (20/77) respect to Greece, show the same limits with an increasing rate of the readiness sub index at the governmental level, thanks to the strong pressure to coercive isomorphism generated by the European legislation, with the Commission "Digital Agenda" of 2011, and by the increasing political role of a new and stronger party like Movimento 5 Stelle, that has a great role in putting digital democracy and digital transparency issue in the national agenda. A lower level of readiness seems to be connected to the peculiar productive systems, characterized more on small firms above all operating in traditional sector (textile, mechanical, etc.), while the level of implementation and impact remain low above all at the social level also due to growing social inequalities after the recent economic crisis.

From the opening of the National Portal Dati.Gov.it in 2011, the number of disclosed dataset increase rapidly (passing form 1.987 in 2012 to 10.551 in 2014), even if the majority of the data released are not in a completely open format considering the 5 Star Scale ${ }^{1}$, as noted in OECD data shown before.

It is possible also underlining, thanks to the experiences collected by the national OD portal, that the diffusion of Open Data initiatives in Italy increases differently in local governments, with a lower commitment of the Southern regions respect to Northern ones, demonstrating again how the more dynamic areas, in an economic and social perspective, are the most suitable environment for the development of OGD strategies.

Figure 6. The Italian Case in the Open Data Barometer (2013)

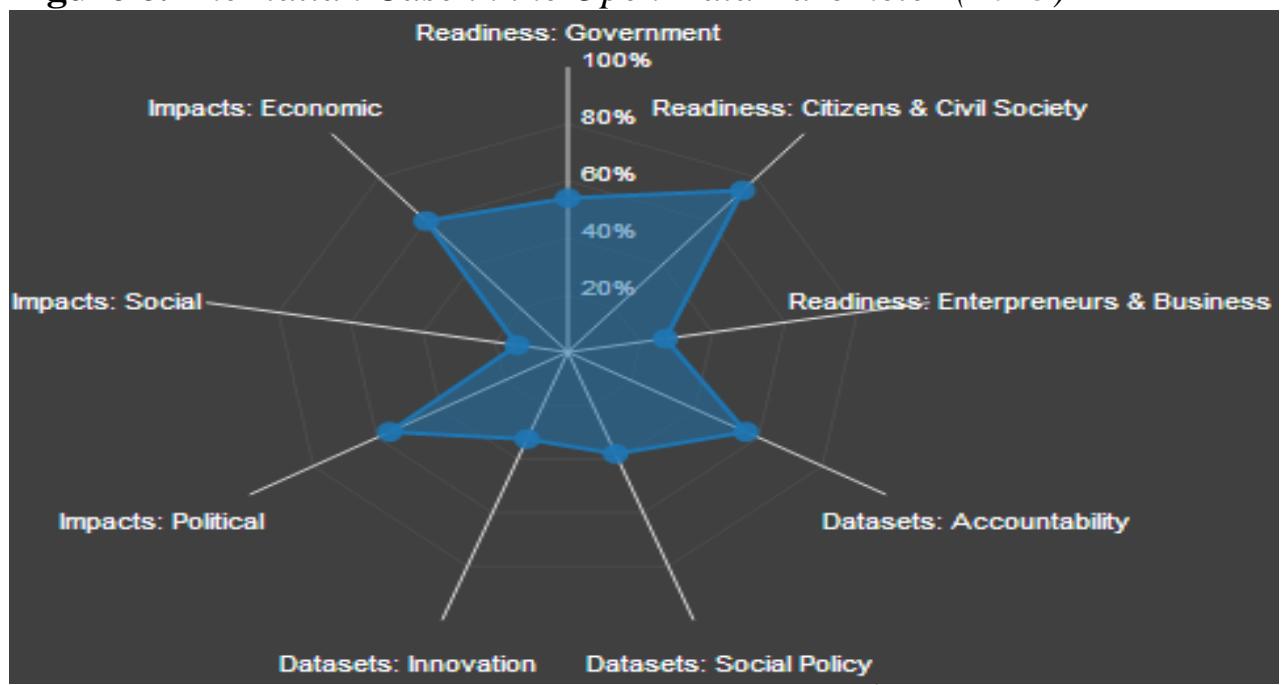

Source: Open Data Institute, 2013 Open Data Barometer Data ${ }^{2}$

\footnotetext{
${ }^{1}$ The five star rating system (www.w3.org/DesignIssues/LinkedData.html), proposed by Tim Berners-Lee in 2010, distinguishes open data into five different groups according to the level of the openness of the format: from data simply available online under an open license (1 star) to the linked open data ( 5 stars) released in formats that allow integration and semantic interoperability between different data-set (Bauer and Kaltenböck, 2011).

${ }^{2}$ visualization of the Open Data Barometer report data http://theodi.github.io/open-databarometer-viz/
} 
The overall shortage in the performance of all the Mediterranean countries in the Continent could be the result of the typical features of the South European Economies, according to Amable's (2003) theorization: a familistic welfare system and a familistic management of companies, an economic system based more on low productivity sectors like tourism, agriculture and manufacturing, and less in ICT sector, the lack of transparency and the high level of political ambiguity in these areas, demonstrated also by the OECD (2012) and World Bank (2013) analysis. This institutional model, defined by Della Sala (2004) a "dysfunctional capitalism", seems to be an unpleasant environment for development of the Open Government Data initiatives

\section{Conclusions}

In conclusion, the influence of contextual factors that characterize the different countries analyzed should not be underestimated. These variables can slow down the drive towards the implementation of effective policies for Open Government. The risk is to determine a "data divide" as a result of specific gaps: cultural, territorial, organizational and regulatory ones. The creation of an Open Data Research Network in 2012 is the evidence of an increasing attention to OGD phenomenon that needs to be studied further to promote a more "conscious" path in order to analyze the Open Data policies and evaluating the resulting effects in the different involved fields.

In particular, the possibility of easily accessing to the public sector information (PSI), and their availability in an open data format, should generate positive effects in three main terms: the first is the augmented possibilities of control on government activities, in order to reduce risks of corruption, thanks to the use of open data by organizations of consumers and citizens active in civic monitoring of public policies, by data journalists or others PA; The second aspect regards the activities of researchers, in different scientific fields that can have a great advantage by the openness and the rapid dissemination and availability of information reducing costs and times for collection and analysis of data; The last point regards benefits for digital economy and in particular the importance of open data availability for developers in order to realize new applications and services.

The open government data movement aims to stimulate innovative ways of cooperation based on the free reuse of the public sector information considered as public goods that can generate social and economic value only with a real and effective policy of open access

\section{References}

AIPG, (2011), Come si fa Open Data? Istruzioni per l'uso per Enti e Amministrazioni Pubbliche, Maggioli, Santarcangelo di Romagna.

Amable B., (2003), The Diversity of Modern Capitalism, Oxford University Press, Oxford. 
Arcidiacono D., Reale G., (2010), Responsabilità sociale d'impresa e welfare locale, «Impresa Sociale», 3, pp. 157-177.

Bauer F., Kaltenböck M., (2011), Linked Open Data: The Essentials, ed. mono, Vienna.

Bauman Z., (2002), Modernità Liquida, Laterza. Roma-Bari.

Beck U., (1999), La società del rischio, Carocci, Roma.

Chesbrough, H. (2003), Open Innovation. The New Imperative for Creating and Profiting from Technology, Harvard Business School Press, Boston.

Cohen E., (2001), "Citizen and consumers in the United States in the century of Mass Consumption", in Daunton M., Hilton M. (eds.), The politics of consumption: material culture and citizenship in Europe and America, Berg, New York.

Della Sala R., (2004), The Italian model of capitalism: on the road between globalization and Europeanization?, «Journal of European Public Policy», 11, pp. 1041-1057.

European Commission (2011), Open data: an engine for innovation, growth and transparent governance, COM(2011) 882 final. http://eur-lex.europa.eu/LexUri Serv/LexUriServ.do?uri=COM:2011:0882:FIN:EN:PDF

Freeman E. R. (1984), Strategic Management: a stakeholder approach, Pitman, Marshfield.

Lévy P. (2008), "A metalanguage for computer augmented collective intelligence", in Tovey M. (eds.), Collective Intelligence: Creating a Prosperous World at Peace, EIN, Oakotn.

Micheletti M., Follesdal A., Stolle D. (2004), Politics Products and Markets, Transaction Pubblishers, New Brunswick.

Marsden C. T., (2009), Net Neutrality "Lite": Regulatory Responses to Broadband Internet Discrimination, University of Essex, Colchester.

Morozov E., (2011), The Net Delusion: The Dark Side of Internet Freedom, New Affairs, New York.

OECD (2012), Entrepreneurship at a Glance 2012, OECD Publishing.

OECD (2013), Government at a Glance 2013, OECD Publishing. http://www.keepee k.com/Digital-Asset-Management/oecd/governance/government-at-a-glance-20 13_gov_glance-2013-en\#page 1

Open Knowledge Foundation (2012), Open Data Handbook, release 1.0.0. http://opendatahandbook.org

Rodotà S., (2004), Tecnopolitica, Laterza, Roma-Bari.

World Bank (2013), Doing Business. Smarter regulation for small and medium size enterprises, Washington.

World Wide Web Foundation and Open Data Institute (2013), edited by Tim Davies, The Open Data Barometer 2013 Global Report, London, UK. http://www.open dataresearch.org/d1/odb2013/Open-Data-Barometer-2013-Global-Report.pdf 
